\title{
Tendon Regeneration and Repair with Stem Cells
}

\author{
S. MacLean, ${ }^{1}$ W. S. Khan, ${ }^{2}$ A. A. Malik, ${ }^{2}$ M. Snow, ${ }^{3}$ and S. Anand ${ }^{1}$ \\ ${ }^{1}$ University of Manchester, Manchester M13 9PL, UK \\ ${ }^{2}$ Royal National Orthopaedic Hospital, Middlesex HA7 4LP, UK \\ ${ }^{3}$ Royal Orthopaedic Hospital, Birmingham B31 2AP, UK \\ Correspondence should be addressed to A. A. Malik, atif01@hotmail.com
}

Received 14 July 2011; Accepted 5 September 2011

Academic Editor: Umile Longo

Copyright (๑) 2012 S. MacLean et al. This is an open access article distributed under the Creative Commons Attribution License, which permits unrestricted use, distribution, and reproduction in any medium, provided the original work is properly cited.

The use of stems cells in tendon repair is of particular interest given the frequency of tendon injuries worldwide together with the technical difficulty often encountered when repairing or augmenting tendons. Stems cells have the capability to differentiate into a variety of different cell types including osteocytes and tenocytes, and if normal architecture of damaged tendon (either macroscopic or microscopic) could be restored, this would significantly improve the management of patients with these injuries. There is already encouraging research on the use of stems cells clinically although considerable further work is required to improve knowledge and clinical applications of stem cells in tissue engineering.

\section{Anatomy and Pathophysiology of Tendon Damage}

Tendons attach muscle to bone and function to transmit tensile loads from muscle to bone and to enable the muscle belly to be at an optimal distance from the joint. The microstructural composition is approximately 20\% cellular (fibroblasts secreting collagen) and 80\% extracellular matrix. The extracellular matrix consists of mainly water, collagen, and ground substance [1].

More than $90 \%$ of collagen in tendons is type 1 with the remainder being type 3 . These molecules are aligned in parallel to form microfibrils, which are further aggregated to form bundles [1]. This allows them to handle high unidirectional tensile loads. Ground substance consists mainly of proteoglycans, glycoproteins, and plasma proteins. These bind the extracellular water in the tendon, helping to stabilise the collagenous skeleton and contributing to the overall tendon strength. Elastin, secreted by fibroblasts, forms highly cross-linked sheets, allowing the tendon to stretch and coil, contributing to tissue recovery after loading.

The tendinous zone of insertion (enthesis) is a progressive structural change from tendon to bone, resulting in increased stiffness and decreased stress concentration. It is often the site of tendinopathic change and injury. It is divided into four zones; parallel collagen fibres at the end of tendon, unmineralised fibrocartilage, and mineralised fibrocartilage, which merges into cortical bone [1].

The blood supply to tendons is inferior to that of most other connective tissues. The blood supply is through a sparse supply of arterioles or a vincula (mesotenon) and subsequent diffusion through the tendon substance. They have a low metabolic rate. Both these factors have implications for the intrinsic healing potential of the tissue [1].

There are a number of factors affecting the biomechanical properties of tendons and subsequent tendinosis (degenerative tendon) or tendinopathy (an inflammatory reaction secondary to rupture or vascular damage) [2]. Ageing results in a decrease in collagen diameter and number. Endocrine factors play a part, and pregnancy is associated with a decreased stiffness of pelvic tendons. Pharmacological agents such as corticosteroids and anabolic steroids are associated with tendon rupture. Systemic disease and genetics affect the intrinsic healing potential. Repetitive microtrauma and fatigue failure often leads to calcification and an inflammatory reaction. Macrotrauma results in the acute rupture of a tendon due to a force above the ultimate tensile strength, either at the tendinous insertion onto bone or in the tendon substance itself.

The healing response is variable and usually poor. There is an initial rapid haemorrhagic and inflammatory phase. This is followed by a proliferative phase, with fibroblast production of new matrix. Remodelling occurs several weeks 
after injury consisting of maturation and orientation of collagen fibres. Although there are external influences affecting tendon repair which can be controlled, there are intrinsic metabolic limitations to healing. Often a surgical solution is necessary to repair or reconstruct tendon. Rotator cuff tears and subsequent repair illustrate the magnitude of the problem. Rotator cuff injuries accounted for 4.4 million outpatient appointments in the US in 2003 [3]. It is estimated that at least $13 \%$ of individuals between the ages of 50 and 59 and $51 \%$ of people over the age of 80 experience rotator cuff injuries [4], and over 50,000 patients in the US require direct repair each year [5]. Despite this, repair can fail up to $40 \%$ of the time, leading to impaired shoulder biomechanics and subsequent weakness and degenerative osteoarthritic changes [6]. Tissue engineering and the use of stem cells has sought to provide a solution to this common cause of musculoskeletal morbidity.

\section{Stem-Cell Potential}

Stem cells may be totipotent, pluripotent, or multipotent, depending on tissue type. Totipotent cells form all the cells and tissues that contribute to the formation of an organism. Only the embryo itself is totipotent. Pluripotent stem cells (PSCs) can form most cells of an organism from all three germ cell layers. Embryonic stem cells present in the fertilised oocyte, zygote, and morula [7]. Pluripotent cells have the ability to expand in vitro almost indefinitely and form tissues from ectoderm, mesoderm, or endoderm. There are concerns about tumour formation in vivo and major ethical concerns, however, which have thus far restricted their use.

Multipotent cells form a number of cells or tissues that are usually restricted to a particular germ layer. Multipotent cells are derived from specific tissue compartments in the adult. The two main types of multipotent stem cell are haemopoietic and mesenchymal type, and both are usually derived from adult bone marrow, but occasionally from fat, skin, periosteum, and muscle. Mesenchymal stem cells (MSCs) are multipotent, capable of differentiating into several connective tissue types including osteocytes, chondrocytes, adipocytes, tenocytes, and myoblasts [8]. Mesenchymal stem cells have the advantage of being easily obtainable in adult tissue and, with the appropriate microenvironment can differentiate into various target tissue types.

Research on tendon healing and the use of stem cells has thus far been limited to animal studies, with the majority using mesenchymal stem cells.

2.1. Mesenchymal Stem Cells. MSCs can arise from a number of sources as already highlighted. Kryger et al. [9] isolated tenocytes, sheath fibroblasts, bone-marrow-derived stem cells, and adipose stem cells from adult rabbits and used them in a flexor tendon model. Although adipose-derived stem cells proliferated faster in culture, at six weeks, there was no difference with regards to cell viability, senescence, or collagen expression.

Tempfer et al. [10] examined biopsies of intact human supraspinatus tendons and showed that stem cell tendon precursors (tenocytes) were present in the tissue. Pryce et al.
[11] showed that TGF beta signalling may play an important role in the recruitment of tenocytes. Mazzocca et al. [12] aspirated bone marrow from the bone anchor tunnel in the humeral head during arthroscopic rotator cuff repair in 23 patients. Using a novel device, in the operating room, stem cells were isolated from this aspirate and their presence and osteogenic potential confirmed. This study showed that stem cell-rich bone marrow is exposed following arthroscopic drilling of the humeral head. These stem cells harbour potential to differentiate into osteoblasts and tenocytes to regenerate the bone-tendon interface. Novel solutions for the recruitment and activation of these cells in combination with growth factors, gene therapy and an appropriate scaffold may provide improved strength of the rotator cuff following surgical repair.

Awad et al. [13] showed that there was a significant improvement in tendon repair when MSCs were injected into patellar tendon defects in rabbits. Compared to a cell-free collagen control at four weeks, MSC-mediated repair tissue demonstrated significant increases in stress, modulus, and strain energy density of $26 \%, 18 \%$, and $33 \%$, respectively. Chong et al. [14] examined the histology and modulus of Achilles tendon defects in rabbits over a 12-week period. Compared to controls, it was shown that at three weeks, there was an improvement in collagen organisation and modulus in the MSC group. By 12 weeks, however, this difference was insignificant, suggesting that MSCs may improve tendon healing in the early stages only.

The tendon-bone interface is a common site of rupture, especially at repetitive low-loading forces, for example, in rotator cuff tendinopathy. Chang et al. [15] examined healing potential of infraspinatus tendon in rabbits at the tendinous insertion using a periosteal graft containing autologous MSCs. Histological examination from 4 to 12 weeks showed gradual progression in healing from fibrotic tissue to mineralised fibrocartilage. There was an associated significant increase in failure load with time compared to controls. Ju et al. [16] used Achilles tendon grafts in a rat anterior cruciate ligament model (ACL). He undertook an ACL reconstruction and then injected the tibiofemoral bone tunnel with MSCs. Tendon-bone analysis at 2 weeks showed the proportion of collagen fibres at the interface tissue was significantly higher in the MSC group compared to controls. At 4 weeks in both groups, the implanted tendon appeared to attach directly to bone. The benefit of injecting MSCs, therefore, may give early benefit in this model. A study by Nourissat et al. [17] evaluated healing at the tendon-bone interface at the Achilles tendon in a rat model. After the tendon-bone interface was destroyed, the tendon was either left to heal, or an injection was given of chondrocytes or MSCs. At 45 days, it was found that cell injection of either chondrocytes or MSCs significantly improved healing compared to controls left to heal without an injection. A new enthesis was produced in the injection groups but not in controls, and in only the MSC group was this organised as in normal enthesis tissue.

The treatment of tendonitis by stem cells was studied by Lacitignola et al. [18] in horses. Tendonitis was induced by an injection of collagenase into the superficial flexor tendons. 
Three weeks later, bone marrow mesenchymal cells, bone marrow mononucleated cells, or controls of fibrin were injected into the tendons. In the stem cell-treated groups, there was significantly improved healing histologically with a higher collagen type 1 to type 3 ratio and improved fibre orientation compared to controls. Another equine flexor tendon model for tendonitis compared MSCs, MSCs with insulin-like growth factor-1 (IGF-1) gene-enhanced MSCs, and controls. Both IGF-1 MSCs and MSC groups showed significantly improved tendon histology at 8 weeks compared to controls [19].

2.2. Pluripotent Stem Cells. Watts et al. [20] reported on the use of an injection of foetal-derived embryonic-like stem cells for superficial flexor tendon injuries in horses. Compared to controls at eight weeks, there was no significant difference in tendon matrix gene expression, proteoglycan, collagen, or DNA content between the tendons. There was, however, improved tissue architecture, tendon size, lesion size, and linear fibre pattern in the lesions treated with stem cells. The tensile strengths of the healing tendons were not tested, however.

Turner et al. [21] reviewed the use of amniotic stem cells for the engineering of a diaphragmatic tendon graft in newborn lambs. Failure rate was higher in the control group (acellular prosthetic graft). Tensile strength testing and collagen levels were significantly higher in the grafts containing stem cells.

The use of stem cell-coated sutures could have obvious theoretical benefits in surgical repair of tendons. Yao et al. [22] evaluated the fats of pluripotential embryonic stem cells seeded to a suture carrier in acellularised, sectioned rabbit Achilles tendon. At day 5, fluorescence under microscopy showed live metabolically active pluripotential cells at the tendon repair site. The same author showed that cell adherence at seven days was greater in FibreWire sutures when first coated with poly-1-lysine or fibronectin [23].

Guest et al. [24] examined the difference between MSCs and embryo-derived PSCs injected into damaged superficial digital flexor tendons in horses. At 90 days following injection, there had no signs of immune reaction to the allogenic PSCs and no sign of tumour formation. Survival rate was greater, with PSCs maintaining a constant level over 90 days in contrast to MSCs which showed less than 5\% survival over ten days and a subsequent decline thereafter. PSCs also showed an ability to migrate to other areas of damaged tendon in contrast to MSCs.

2.3. Tissue Engineering for Tendon Regeneration. There are now several studies illustrating the potential for the use of stem cells not only in tendon repair, but also other their use in other tissue engineering applications [25-29]. Several studies have shown that a mechanical stimulus improves tendon healing. It has been shown in patellar tendon defects in rabbits that two weeks of in vitro mechanical stimulation significantly increased collagen type 1 and collagen type 3 gene expression of stem cell-collagen sponge constructs. These constructs exhibited 2.5 times increased linear stiffness and 4 times the linear modulus of controls [30]. The degree of mechanical loading has been shown to affect cell differentiation. One study showed that low mechanical in vitro stretching of MSCs into tenocytes, where as larger stretching at $8 \%$ induced differentiation into adipocytes, chondrocytes, and osteocytes [31]. In clinical practise, lipid accumulation and calcification in a healing tendon may lead to pain and a detrimental functional outcome.

In vivo, the extracellular matrix of tendon provides fibroblasts with the architecture to support development and function. During tissue engineering, therefore, a scaffold is needed to mimic this matrix. The optimal cell: matrix ratio to support tendon function is debated. Juncosa-Melvin et al. [32] examined cell: collagen ratios in Achilles tendon defects in rabbits. It was shown that constructs with a lower cell density at 12 weeks achieved higher stiffness and modulus values. Nirmalanandhan et al. [33] showed that above a threshold value of cell density, percentage reductions in collagen concentration influence contraction kinetics more than equivalent percentage increases in cell seeding density. The alignment of stem cells on scaffolds may be important. Yin et al. [34] showed that foetal stem cells placed in randomly oriented scaffolds in vitro led to osteogenic differentiation. In contrast, aligned nanofibres induced the formation of spindle-shaped cells and tendon-like tissue. Obviously, controlling scaffold conditions is vital to the effective differentiation of these cells and the ultimate mechanical properties of the healing tissue.

Butler et al. [35] found that in rabbits with patellar tendon defects, there appeared to be 4 important factors which improved the biomechanical properties of the healing tendon. Replacing the suture with end posts in culture and lowering the MSC concentration in cell-scaffold constructs resulted in failure forces greater than peak in vivo forces that were measured for all activities and tangential stiffness similar to normal tendon. Augmenting the scaffold gel with a type 1 collagen sponge increased repair stiffness, and mechanically stimulating these constructs further improved biomechanics in the healed tendon.

2.3.1. Use of Growth Factors in Tissue Engineering. Recently, Gulotta et al. [36] has highlighted the importance of gene expression in stem cells for tendon healing. In a rat supraspinatus model, MSCs after injection were present and metabolically active, but no difference in the biomechanical strength of the repairs, the cross-sectional area, peak stress to failure, or stiffness compared to controls could be found. A further study compared an MSC group and a group who had received adenoviral MT1 matrix metalloproteinasetransduced MSCs (Ad-MT1-MMP). Although no difference was found at 2 weeks, at 4 weeks, the Ad-MT1-MMP group had significantly more fibrocartilage, higher load to failure, stress to failure, and stiffness values as compared to MSCs [37]. It has also been shown that MSCs expressing BMP-2 and the transcription factor Smad8ca lead to differentiation into a tenocyte lineage [38]. It has been proposed that expression of Smad8ca lead to the production of MMPs. Shahab-Osterloh et al. [39] showed that MSCs with adenoviral-induced Smad8ca and BMP-2 exhibit both tendinous and osteogenic properties in mice and can aid formation, 
therefore, of bone-tendon interface. Numerous other studies highlight the beneficial effect of BMP in tendon-bone interface healing [40].

The quality of tendon that forms from bioengineering may be a concern still, with ectopic bone formation being a problem in the healing tissue. Harris et al. [41] showed that this is likely related to alkaline phosphatase activity and may be higher in $3 \mathrm{D}$ in vitro constructs compared to tissue engineering on a $2 \mathrm{D}$ monolayer.

\section{Summary}

Tendon healing is limited by numerous intrinsic and extrinsic factors [42-47]. These have implications for the athlete in a "macrotrauma" acute rupture setting or in repetitive microtrauma leading to tendonitis. Like all connective tissues, tendon is vulnerable to the effects of ageing, inevitably leading to cell senescence of tenocytes, resulting in an extracellular matrix devoid of collagen and weakened tissue. The principles of tissue engineering involve a complex interplay of factors [48-52]. Local delivery of growth factors, the use of plasmids, and scaffolds are several. These in combination with stem cells or genetically modified stem cells have been shown to contribute to tendon healing in numerous animal studies [53-56]. Concerns arise as to tumour formation and immune reactions to allogenic sources, and there are obvious ethical considerations. The use of stem cells is a promising treatment in the armamentarium of the physician or surgeon, but further research is needed to decide on the optimal strategy in humans.

\section{References}

[1] C. C. Tai and A. Williams, "Ligaments and tendons," in Basic Orthopaedic Sciences, Ramachandram, Ed., chapter 8, pp. 7178, Hodder-Arnold, London, UK, 2007.

[2] A. Hoffmann and G. Gross, "Tendon and ligament engineering in the adult organism: mesenchymal stem cells and genetherapeutic approaches," International Orthopaedics, vol. 31, no. 6, pp. 791-797, 2007.

[3] C. J. DeFrances, M. J. Hall, and M. N. Podgornik MN., “2003 summary: national hospital discharge survey," Advance Data from Vital and Health Statistics no. 359, National Center for Health Statistics, Hyattsville, Md, USA, 2005.

[4] S. Tempelhof, S. Rupp, and R. Seil, "Age-related prevalence of rotator cuff tears in asymptomatic shoulders," Journal of Shoulder and Elbow Surgery, vol. 8, no. 4, pp. 296-299, 1999.

[5] C. Milgrom, M. Schaffler, S. Gilbert, and M. Van Holsbeeck, "Rotator-cuff changes in asymptomatic adults. The effect of age, hand dominance and gender," Journal of Bone and Joint Surgery-Series B, vol. 77, no. 2, pp. 296-298, 1995.

[6] A. Miniaci and M. MacLeod, "Transfer of the latissimus dorsi muscle after failed repair of a massive tear of the rotator cuff. A two to five-year review," Journal of Bone and Joint SurgerySeries A, vol. 81, no. 8, pp. 1120-1127, 1999.

[7] A. Bongso and E. H. Lee, "Stem cells: their definition, classification and sources," in Stem Cells: From Bench to Bedside, A. Bongso and E. H. Lee, Eds., p. 1, World Scientific Publishing, Singapore, 2005.
[8] A. I. Caplan, "The mesengenic process," Clinics in Plastic Surgery, vol. 21, no. 3, pp. 429-435, 1994.

[9] G. S. Kryger, A. K. S. Chong, M. Costa, H. Pham, S. J. Bates, and J. Chang, "A Comparison of tenocytes and mesenchymal stem cells for use in flexor tendon tissue engineering," Journal of Hand Surgery, vol. 32, no. 5, pp. 597-605, 2007.

[10] H. Tempfer, A. Wagner, R. Gehwolf et al., "Perivascular cells of the supraspinatus tendon express both tendon- and stem cellrelated markers," Histochemistry and Cell Biology, vol. 131, no. 6, pp. 733-741, 2009.

[11] B. A. Pryce, S. S. Watson, N. D. Murchison, J. A. Staverosky, N. Dünker, and R. Schweitzer, "Recruitment and maintenance of tendon progenitors by TGF- $\beta$ signaling are essential for tendon formation," Development, vol. 136, no. 8, pp. 13511361, 2009.

[12] A. D. Mazzocca, M. B. R. McCarthy, D. M. Chowaniec, M. P. Cote, R. A. Arciero, and H. Drissi, "Rapid isolation of human stem cells (connective tissue progenitor cells) from the proximal humerus during arthroscopic rotator cuff surgery," American Journal of Sports Medicine, vol. 38, no. 7, pp. 14381447, 2010.

[13] H. A. Awad, D. L. Butler, G. P. Boivin et al., "Autologous mesenchymal stem cell-mediated repair of tendon," Tissue Engineering, vol. 5, no. 3, pp. 267-277, 1999.

[14] A. K. Chong, J. Chang, and J. C. Go, "Mesenchymal stem cells and tendon healing," Frontiers in Bioscience, vol. 14, pp. 45984605, 2009.

[15] C. H. Chang, C. H. Chen, C. Y. Su, H. T. Liu, and C. M. Yu, "Rotator cuff repair with periosteum for enhancing tendonbone healing: a biomechanical and histological study in rabbits," Knee Surgery, Sports Traumatology, Arthroscopy, vol. 17, no. 12, pp. 1447-1453, 2009.

[16] Y. J. Ju, T. Muneta, H. Yoshimura, H. Koga, and I. Sekiya, “Synovial mesenchymal stem cells accelerate early remodeling of tendon-bone healing," Cell and Tissue Research, vol. 332, no. 3, pp. 469-478, 2008.

[17] G. Nourissat, A. Diop, N. Maurel et al., "Mesenchymal stem cell therapy regenerates the native bone-tendon junction after surgical repair in a degenerative rat model," PLoS ONE, vol. 5, no. 8, Article ID e12248, 2010.

[18] L. Lacitignola, A. Crovace, G. Rossi, and E. Francioso, "Cell therapy for tendinitis, experimental and clinical report," Veterinary Research Communications, vol. 32, no. 1, pp. S33-S38, 2008.

[19] L. V. Schnabel, M. E. Lynch, M. C. H. Van der Meulen, A. E. Yeager, M. A. Kornatowski, and A. J. Nixon, "Mesenchymal stem cells and insulin-like growth factor-I gene-enhanced mesenchymal stem cells improve structural aspects of healing in equine flexor digitorum superficialis tendons," Journal of Orthopaedic Research, vol. 27, no. 10, pp. 1392-1398, 2009.

[20] A. E. Watts, A. E. Yeager, O. V. Kopyov, and A. J. Nixon, "Fetal derived embryonic-like stem cells improve healing in a large animal flexor tendonitis model," Stem Cell Research and Therapy, vol. 2, no. 1, article 4, 2011.

[21] C. G. Turner, J. D. Klein, S. A. Steigman et al., "Preclinical regulatory validation of an engineered diaphragmatic tendon made with amniotic mesenchymal stem cells," Journal of Pediatric Surgery, vol. 46, no. 1, pp. 57-61, 2011.

[22] J. Yao, T. Korotkova, J. Riboh, A. Chong, J. Chang, and R. L. Smith, "Bioactive sutures for tendon repair: assessment of a method of delivering pluripotential embryonic cells," Journal of Hand Surgery, vol. 33, no. 9, pp. 1558-1564, 2008. 
[23] J. Yao, T. Korotkova, and R. L. Smith, "Viability and proliferation of pluripotential cells delivered to tendon repair sites using bioactive sutures- an in vitro study," Journal of Hand Surgery, vol. 36, no. 2, pp. 252-258, 2011.

[24] D. J. Guest, M. R. W. Smith, and W. R. Allen, "Equine embryonic stem-like cells and mesenchymal stromal cells have different survival rates and migration patterns following their injection into damaged superficial digital flexor tendon," Equine Veterinary Journal, vol. 42, no. 7, pp. 636-642, 2010.

[25] F. Rayanmarakkar, W. S. Khan, and T. E. Hardingham, "Principles of tissue engineering approaches for tendons, skin, nerves and blood vessels in the hand," in Hand Surgery: Preoperative Expectations, Techniques and Results, R. H. Beckingsworth, Ed., pp. 85-96, Nova Science Publishers, New York, NY, USA, 2009.

[26] E. Oragui, N. Sachinis, N. Hope, and W. S. Khan, "Short communication: tendon regeneration and repair, and the role of mesenchymal stem cells," in Mesenchymal Stem Cells, Y. Xiao, Ed., Nova Science Publishers, New York, NY, USA, 2011.

[27] F. Rayanmarakkar, W. S. Khan, A. Malik, and T. E. Hardingham, "Principles of tissue engineering approaches in plastic surgery: tendons and skin," Stem Cell Research, vol. 2, no. 1, pp. 1-10, 2010.

[28] N. A. Siddiqui, J. M. L. Wong, and W. S. Khan, "Stem cells for tendon and ligament tissue engineering and regeneration," Journal of Stem Cells. In press.

[29] J. Donaldson and W. S. Khan, "Functional tissue engineering for rotator cuff tendons," Journal of Stem Cells. In press.

[30] N. Juncosa-Melvin, K. S. Matlin, R. W. Holdcraft, V. S. Nirmalanandhan, and D. L. Butler, "Mechanical stimulation increases collagen type I and collagen type III gene expression of stem cell-collagen sponge constructs for patellar tendon repair," Tissue Engineering, vol. 13, no. 6, pp. 1219-1226, 2007.

[31] A. Y. Zhang and J. Chang, "Tissue engineering of flexor tendons," Clinics in Plastic Surgery, vol. 30, no. 4, pp. 565-572, 2003.

[32] N. Juncosa-Melvin, G. P. Boivin, M. T. Galloway, C. Gooch, J. R. West, and D. L. Butler, "Effects of cell-to-collagen ratio in stem cell-seeded constructs for Achilles tendon repair," Tissue Engineering, vol. 12, no. 4, pp. 681-689, 2006.

[33] V. S. Nirmalanandhan, M. S. Levy, A. J. Huth, and D. L. Butler, "Effects of cell seeding density and collagen concentration on contraction kinetics of mesenchymal stem cell-seeded collagen constructs," Tissue Engineering, vol. 12, no. 7, pp. 1865-1872, 2006.

[34] Z. Yin, X. Chen, J. L. Chen, and H. W. Ouyang, "Stem cells for tendon tissue engineering and regeneration," Expert Opinion on Biological Therapy, vol. 10, no. 5, pp. 689-700, 2010.

[35] D. L. Butler, N. Juncosa-Melvin, G. P. Boivin et al., "Functional tissue engineering for tendon repair: a multidisciplinary strategy using mesenchymal stem cells, bioscaffolds, and mechanical stimulation," Journal of Orthopaedic Research, vol. 26, no. 1, pp. 1-9, 2008.

[36] L. V. Gulotta, D. Kovacevic, J. R. Ehteshami, E. Dagher, J. D. Packer, and S. A. Rodeo, "Application of bone marrowderived mesenchymal stem cells in a rotator cuff repair model," American Journal of Sports Medicine, vol. 37, no. 11, pp. 2126 2133, 2009.

[37] L. V. Gulotta, D. Kovacevic, S. Montgomery, J. R. Ehteshami, J. D. Packer, and S. A. Rodeo, "Stem cells genetically modified with the developmental gene MT1-MMP improve regeneration of the supraspinatus tendon-to-bone insertion site,"
American Journal of Sports Medicine, vol. 38, no. 7, pp. 1429$1437,2010$.

[38] A. Hoffmann and G. Gross, "Tendon and ligament engineering in the adult organism: mesenchymal stem cells and genetherapeutic approaches," International Orthopaedics, vol. 31, no. 6, pp. 791-797, 2007.

[39] S. Shahab-Osterloh, F. Witte, A. Hoffmann et al., "Mesenchymal stem cell-dependent formation of heterotopic tendonbone insertions (osteotendinous junctions)," Stem Cells, vol. 28, no. 9, pp. 1590-1601, 2010.

[40] D. Kovacevic and S. A. Rodeo, "Biological augmentation of rotator cuff tendon repair," Clinical Orthopaedics and Related Research, vol. 466, no. 3, pp. 622-633, 2008.

[41] M. T. Harris, D. L. Butler, G. P. Boivin, J. B. Florer, E. J. Schantz, and R. J. Wenstrup, "Mesenchymal stem cells used for rabbit tendon repair can form ectopic bone and express alkaline phosphatase activity in constructs," Journal of Orthopaedic Research, vol. 22, no. 5, pp. 998-1003, 2004.

[42] F. Rayanmarakkar, W. S. Khan, A. Malik, and T. E. Hardingham, "Principles of tissue engineering approaches in plastic surgery: tendons and skin," Stem Cell Research, vol. 2, no. 1, pp. 1-10, 2010.

[43] E. Oragui, N. Sachinis, N. Hope, and W. S. Khan, "The role of mesenchymal stem cells in tendon regeneration and repair," Stem Cell Research. In press.

[44] M. Al-Rashid and W. S. Khan, "The role of stem cells in ligament repair," Stem Cell Research. In press.

[45] G. Thanabalasundaram, N. Arumalla, H. D. Tailor, and W. S. Khan, "Regulation of differentiation of mesenchymal stem cells into musculoskeletal cells," Current Stem Cell Research \& Therapy. In press.

[46] J. Donaldson, W. S. Khan, and A. Hazlerigg, "Functional tissue engineering for rotator cuff tendons," Journal of Stem Cells. In press.

[47] A. Malik and W. S. Khan, "Editorial: stem cell applications and tissue engineering approaches in orthopaedic surgery and musculoskeletal medicine," Current Stem Cell Research \& Therapy. In press.

[48] N. A. Siddiqui, J. M. L. Wong, W. S. Khan, and A. Hazlerigg, "Stem cells for tendon and ligament tissue engineering and regeneration," Journal of Stem Cells. In press.

[49] P. Mafi, S. Hindocha, R. Mafi, M. Griffin, and W. S. Khan, "Sources of adult mesenchymal stem cells applicable for musculoskeletal applications- a systematic review of the literature," The Open Orthopaedics Journal, vol. 5, no. 2, pp. 238-244, 2011.

[50] L. Kennard, H. D. Tailor, G. Thanabalasundaram, and W. S. Khan, "Advances and developments in the use of human mesenchymal stem cells_a few considerations," The Open Orthopaedics Journal, vol. 5, no. 2, pp. 245-249, 2011.

[51] E. Oragui, M. Nannaparaju, and W. S. Khan, "The Role of bioreactors in tissue engineering for musculoskeletal applications," The Open Orthopaedics Journal, vol. 5, no. 2, pp. 264267, 2011.

[52] M. Kanitkar, H. D. Tailor, and W. S. Khan, "The use of growth factors and mesenchymal stem cells in orthopaedics," The Open Orthopaedics Journal, vol. 5, no. 2, pp. 268-274, 2011.

[53] W. S. Khan, "Foreword: stem cell applications and tissue engineering approaches in sports medicine- from bench to bedside," Journal of Stem Cells, vol. 5, no. 4, 2011. 
[54] B. A. Tucker, S. S. Karamsadkar, W. S. Khan, and P. Pastides, "The role of bone marrow derived mesenchymal stem cells in sports injuries," Journal of Stem Cells. In press.

[55] J. S. Mohal, H. D. Tailor, and W. S. Khan, "Sources of adult mesenchymal stem cells and their applicability for musculoskeletal applications," Current Stem Cell Research \& Therapy. In press.

[56] A. Mahapatra and W. S. Khan, "Editorial: tissue engineering in orthopaedics and musculoskeletal sciences," The Open Orthopaedics Journal, vol. 5, pp. 234-237, 2011. 

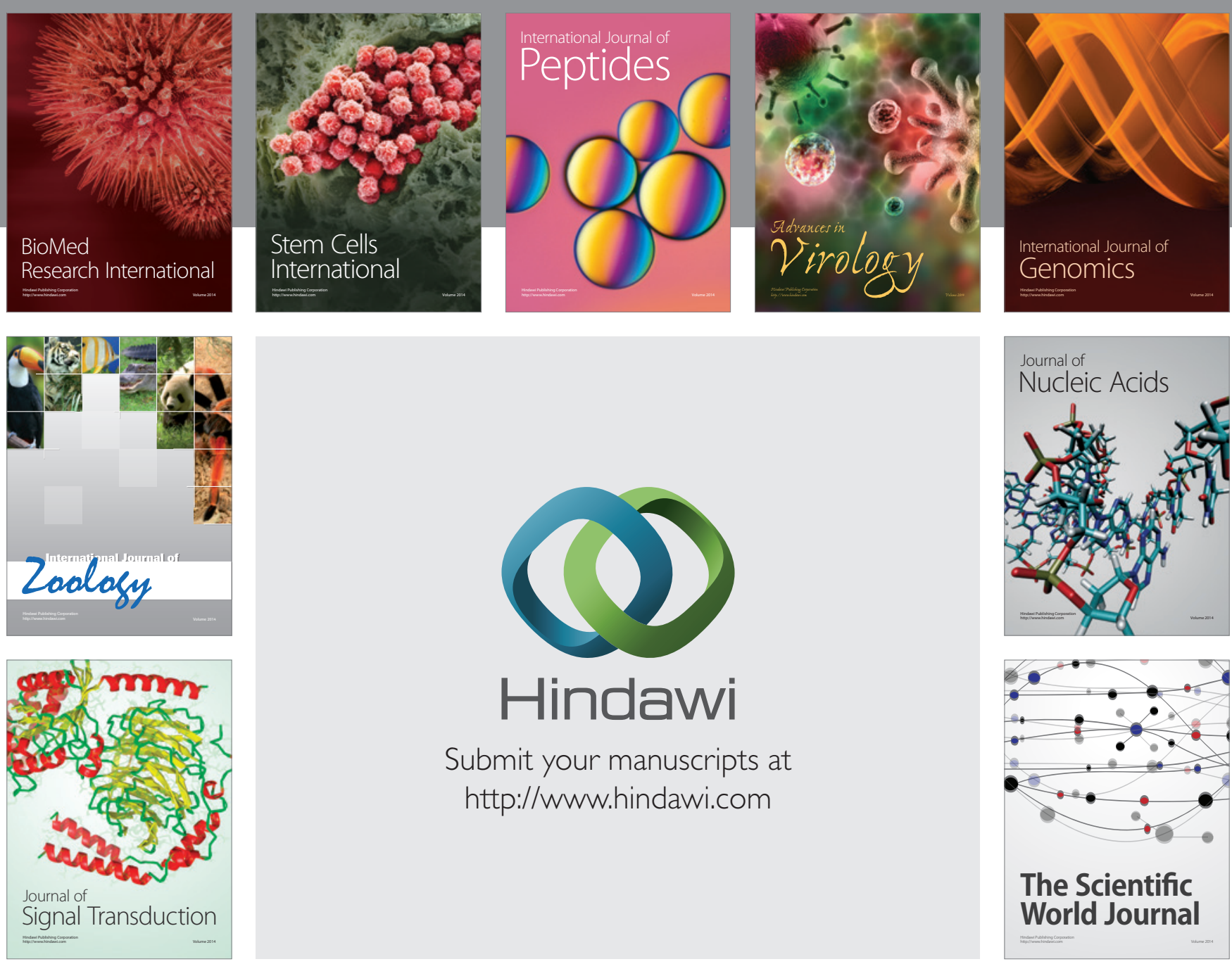

Submit your manuscripts at

http://www.hindawi.com
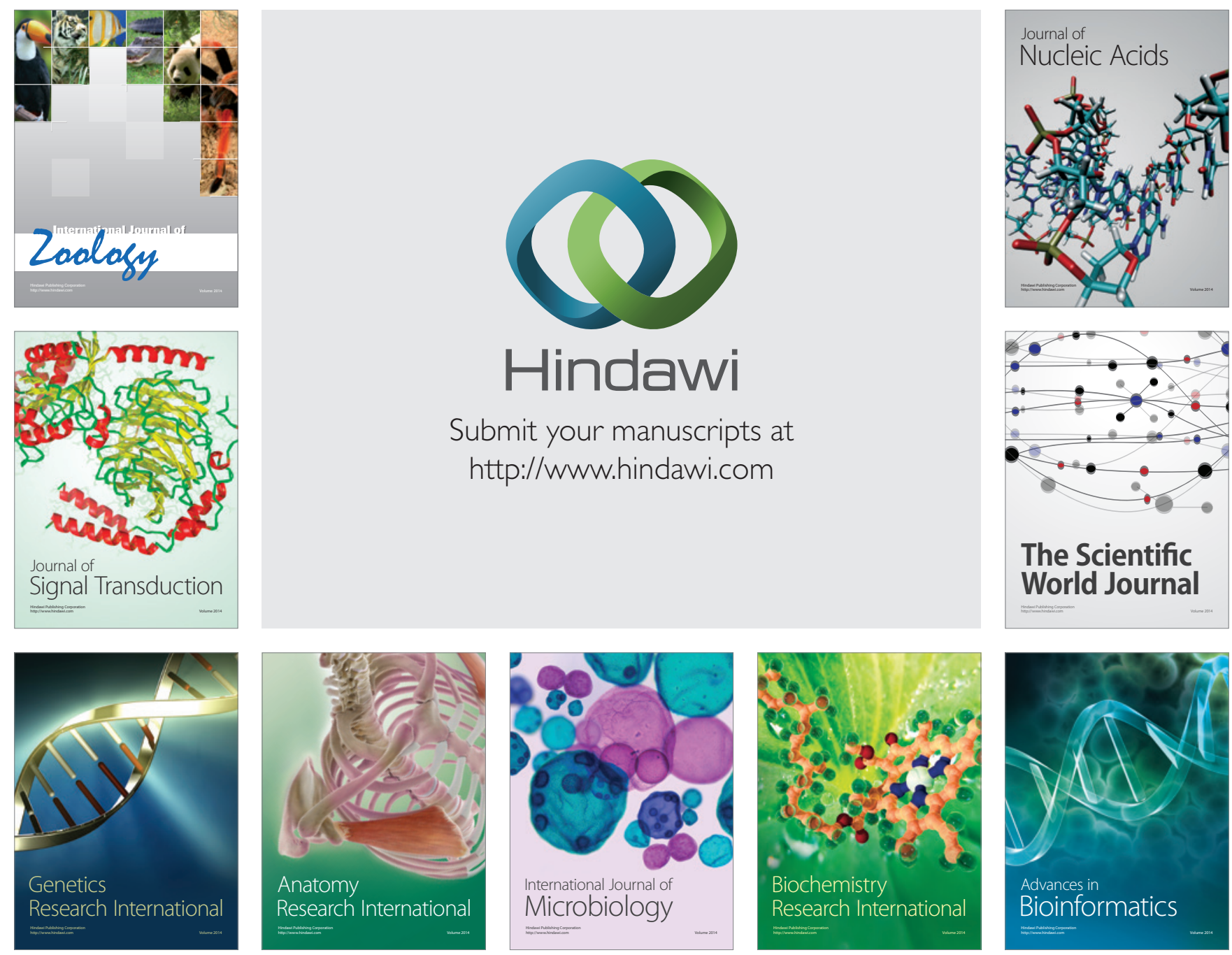

The Scientific World Journal
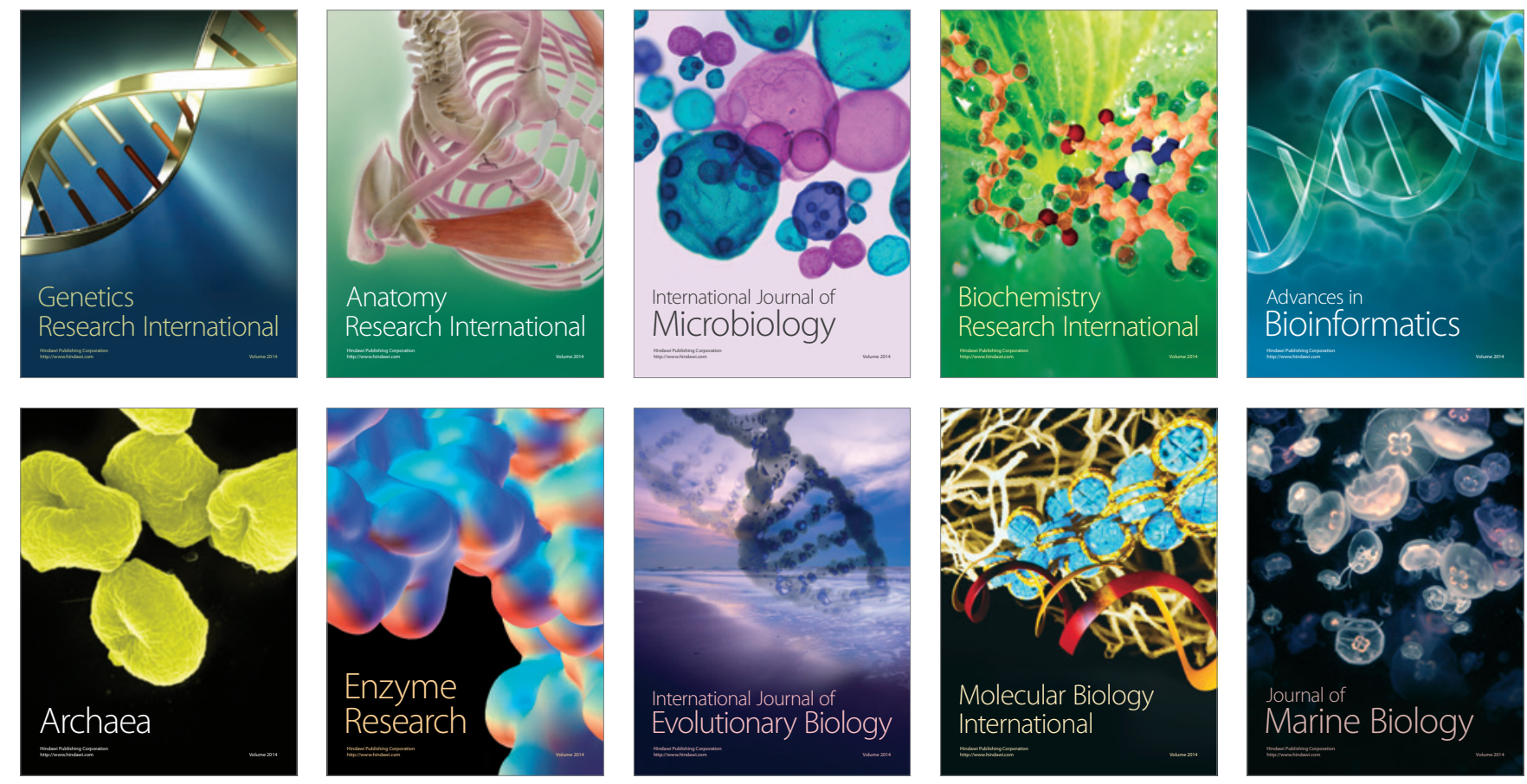